\title{
DEFENSOR DEL PUEBLO Y DEFENSORÍAS AUTONÓMICAS: REFLEXIONES SOBRE SUS RELACIONES Y POSICIÓN RECÍPROCA
}

\author{
JOSÉ JULIO FERNÁNDEZ RODRÍGUEZ ${ }^{1}$ \\ Profesor Titular de Derecho Constitucional \\ Universidad de Santiago de Compostela
}
SUMARIO
I. Introducción.
II. Aproximación a la naturaleza de estas instituciones.
III. La importancia de la cuestión: compe- tencias concurrentes y desajustes actua- les.
IV. Los principios de relación.
V. Manifestaciones de tales relaciones.
VI. El caso del Estatuto de Cataluña.
VII. Conclusiones.

\section{INTRODUCCIÓN}

El devenir del tiempo ha confirmado el éxito de la figura del Ombudsman, figura que en la actualidad se encuentra en todas las latitudes del planeta. Se trata, sin duda, de una de las instituciones más extendidas del Derecho Público. La causa de ello pasa tanto por sus propias potencialidades como por el asentamiento en la opinión pública de la relevancia de los derechos fundamentales y la eficacia que en su defensa pueden desempeñar las defensorías del pueblo. No sólo estamos ante una institución asentada en el mundo democrático sino también ante una figura que puede enfrentarse con éxito a los retos que el siglo XXI plantea a los derechos de la ciudadanía y a las dificultades que traban la buena administración ${ }^{2}$.

1 Vicevaledor do Pobo (Galicia).

2 Permítasenos remitir, para una ojeada a los desafíos presentes, a nuestro trabajo "Los nuevos retos para las defensorías del pueblo: bases para una reflexión", en VV. AA., Memoria del X Congreso Iberoamericano de Derecho Constitucional, Tomo I, IDEMSA, Lima, 2009, pág. 237 y ss. 
Sin duda, a estas alturas, el punto de partida del tema que ahora nos concierne es sobradamente conocido: la previsión constitucional del Defensor del Pueblo, ubicada en el art. 54 de nuestra Carta Magna, no hace ninguna alusión a la existencia de figuras similares en las Comunidades Autónomas ${ }^{3}$. Dicho precepto se interpretó en el sentido de que tales figuras eran posibles pues no se establece ningún tipo de monopolio estatal en este ámbito. De esta forma, la LO 3/1981, del Defensor del Pueblo, contempló la posibilidad de la existencia de entidades similares (art. 12.2), y los estatutos de autonomía comenzaron a preverlas, desarrollándose e implementándose poco a poco. A día de hoy son trece las comunidades en las que existe efectivamente esta figura (aunque no en todas está contemplada a nivel estatutario): Andalucía, Aragón, Canarias, Castilla-León, Castilla-La Mancha, Cataluña, Comunidad Valenciana, Galicia, La Rioja, Navarra, País Vasco, Principado de Asturias y Región de Mur$\mathrm{cia}^{4}$. Esta situación da lugar a la necesidad de analizar jurídicamente el esquema de relaciones, complejas y poco claras, que se producen entre el órgano constitucional y los comisionados parlamentarios autonómicos.

Una precisión adicional para poner fin al presente apartado introductorio: como se refleja en el propio título de este trabajo, en nuestro análisis no vamos a hacer referencia a otro tipo de defensorías que no sean el Defensor del Pueblo ni sus homólogos autonómicos. Por lo tanto, no entraremos ni en los defensores locales ni sectoriales, que presentan, cada uno, una problemática específica que exige un planteamiento propio, que no podemos desarrollar en este momento puesto que nos desviaría de nuestro hilo argumental. Asimismo, no queremos agotar el tema, sólo reflexionar sobre sus ejes básicos. Lo contrario llevaría a una monografía y a otra forma de enfoque.

\section{APROXIMACIÓN A LA NATURALEZA DE ESTAS INSTITUCIONES}

Antes de entrar en cuestiones más concretas relativas a las relaciones que se producen entre los órganos que dan título a este trabajo, semeja conveniente detenernos, si bien brevemente, en la naturaleza de los mismos, pues las diferencias que existen en ello tienen su repercusión en las susodichas relaciones.

El Defensor del Pueblo es un órgano de relevancia constitucional, previsto, como ya hemos dicho, en el art. 54 de la Constitución en vigor. Su po-

3 Las enmiendas que se presentaron en el proceso constituyente para incorporar las defensorías territoriales no tuvieron éxito (una de F. LETAMENDÍA y otra de J.M. BANDRÉS).

4 Son doce los estatutos que contemplan esta figura. Las previsiones de los Estatutos de Cantabria, de Extremadura y de las Islas Baleares sobre las defensorías no han sido por el momento implementadas, aunque en las Islas Baleares existe ley de desarrollo (la Ley 1/1993, del Sindic de Greuges de las Islas Baleares). En cambio, los ombudspersons de Asturias, Castilla-La Mancha, Murcia y Navarra no están previstos en sus estatutos sino directamente en sus leyes regulatorias. Por lo tanto, la Comunidad Autónoma de Madrid es la única en la que no hay ninguna previsión al respecto. 
sición en la arquitectura constitucional lo convierte en órgano del Estado global (Gesamtstaat) con competencias en todo el territorio. Desde un punto de vista formal sería un órgano constitucional, por la previsión expresa del mismo en la Carta Magna ${ }^{5}$. Sin embargo, este concepto de "órgano constitucional" se suele usar más bien en un sentido material, que exige su participación en la construcción de las decisiones políticas relevante de dirección estatal ${ }^{6}$. Desde este punto de vista el Defensor del Pueblo no sería un órgano constitucional, sino más bien un órgano estatal superior, eso sí, de dimensión o relevancia constitucional, como ya hemos dicho.

Frente a ello, las defensorías autonómicas carecen de esa dimensión constitucional. Serán las propias Comunidades Autónomas las que, en uso de poder de autodisposición organizativa, creen o no la figura del ombudsperson en su territorio.

Sin embargo, estas diferencias en la naturaleza jurídica no generan una relación de jerarquía, pues no hay ningún dato normativo que avale tal extremo. Aunque, como acabamos de decir, el Defensor del Pueblo forma parte del ordenamiento del Estado global (antes que del Estado "central"), ello no supone necesariamente la entrada en escena del principio de jerarquía ${ }^{7}$. Del conjunto de regulación (constitucional, estatutaria, legal y reglamentaria) no se puede afirmar en modo alguno semejante jerarquía. La práctica real de funcionamiento tampoco lleva a ello, ni está en el ánimo de ninguno de los agentes implicados.

No obstante, algún autor sí ha visto supremacía constitucional en el Defensor del Pueblo, opinión que no compartimos ${ }^{8}$. En cambio, creemos que podría hablarse, en todo caso, de cierta preeminencia como correlato de la di-

5 Desde este punto de vista, la exclusiva previsión en la Ley Fundamental convertiría al órgano en constitucional.

6 Afirma GARCÍA-PELAYO que resulta necesaria la "participación en la dirección política del Estado; es decir, la formación de la voluntad estatal, la dirección del poder supremo del Estado, las funciones de dirección y estructuración del Estado" (GARCÍA-PELAYO, M., "El status del Tribunal Constitucional", Revista Española de Derecho Constitucional, núm. 1, 1981, págs. 13 y ss.).

7 Las relaciones entre el ordenamiento estatal "central" y los ordenamientos autonómicos están presididas, como es sabido, por el principio de competencia. Simplificando la problemática, podría decirse que el principio de autonomía política impide que opere la jerarquía. En cambio, en las relaciones del ordenamiento constitucional global con los ordenamientos estatal y autonómico sí puede tener aplicación el principio de jerarquía, habida cuenta la supremacía de la Constitución. Sin embargo, en el tema de los ombudspersons no hay ninguna referencia concreta que sirva para justificar la jerarquía, aunque estemos hablando de relaciones entre el ordenamiento global y los ordenamientos autonómicos.

8 Se trata de posiciones hoy en día minoritarias, y ya alejadas en el tiempo: GIL-ROBLES, A., "El Defensor del Pueblo e instituciones similares de ámbito territorial reducido", Revista de la Facultad de Derecho de la Universidad Complutense, núm. 4, 1981, pág. 44; BAR, A. "La regulación jurídica de los defensores del pueblo regionales, ¿̨cooperación o conflicto?», Revista de Derecho Político, UNED, núms. 18-19, 1983, págs. 92 y 107. ROCA ROCA habla de "superioridad funcional y competencial" (ROCA ROCA, E., "El Defensor del Pueblo en las Comunidades Autónomas", Revista de la Facultad de Derecho de la Universidad de Granada, núm. 14, 1987, pág. 214). 
ferente naturaleza jurídica ya mostrada anteriormente. Por lo tanto, desde esta posición, se puede decir que al Defensor del Pueblo como órgano constitucional le corresponde la preeminencia en las relaciones entre las diversas defensorías.

Con relación a la regulación estatutaria ${ }^{9}$, en algunos casos tenemos elementos que permiten sostener la aludida preeminencia, aunque en otros supuestos la previsión posibilita abogar por la posición igualitaria. Respecto a los primeros, habría que citar el Estatuto vasco (art. 15) y el gallego (art. 14), que hablan de la creación de sus defensores autonómicos "con respeto a la institución" establecida por el art. 54 de la Constitución. También en esta línea se encuentran el Estatuto de La Rioja (art. 22) y de Aragón (art. 56), al emplear la fórmula "sin perjuicio de la institución" prevista en el art. 54 de la Constitución". A su vez, el Estatuto de Canarias (art. 14), de Castilla y León (art. 18) e Islas Baleares (art. 51) sólo se refieren al principio de coordinación, principio que analizaremos más abajo pero que puede entenderse que está en la línea de la preeminencia del órgano constitucional.

En cambio, otros estatutos se sitúan más bien en la posición igualitaria. En este sentido, el Estatuto de Cataluña (art. 78.2) y el de Andalucía (art. 128) hablan de colaboración entre su ombudsperson y el Defensor. Por su parte, el Estatuto de Extremadura menciona del Defensor del Pueblo, pero para decir que una "ley de la Asamblea creará y regulará el régimen jurídico y funcionamiento de un órgano similar" al mismo, lo que no proporciona ningún dato sobre la aludida preeminencia. El Estatuto de Cantabria (art. 16) y el de la Comunidad Valenciana (art. 38) no aluden para nada al Defensor del Pueblo estatal.

Haciendo un esfuerzo simplificador podría decirse que hemos asistido a una especie de evolución, a nivel de opinión, en la posición recíproca de estos órganos: desde la preeminencia del Defensor estatal hasta la defensa de una situación absolutamente igualitaria. Es cierto que alguna de las reformas estatutarias más recientes podría corroborarlo, pero entendemos que la interpretación constitucional más razonable apunta a esa preeminencia que acabamos de defender en los párrafos anteriores. Téngase en cuenta que parte de los estatutos reformados en la última oleada siguen enmarcados en esta línea (como los de Aragón o Castilla y León), por lo que no vemos justificada semejante evolución de las opiniones al respecto, al menos con base en el Derecho Positivo.

\section{LA IMPORTANCIA DE LA CUESTIÓN: COMPETENCIAS CONCURRENTES Y DESAJUSTES ACTUALES}

El tema de las relaciones entre Defensor del Pueblo y las defensorías autonómicas no es una cuestión meramente teórica, que sirva para explicitar las

9 Como dijimos en la nota 4 son doce los estatutos que prevén esta figura. 
posiciones respectivas en el entramado del sistema público, sino que también, y sobre todo, es un tema práctico que afecta al correcto cumplimiento de las funciones que tienen asignadas, y a la adecuada defensa de los derechos de los ciudadanos que acuden a dichos órganos.

La relevancia de este análisis también se explica porque se ha producido una especie de evolución en las opiniones al respecto, evolución que acabamos de comentar y que podría sintetizarse como el paso de la coordinación a la cooperación. Es decir, desde una situación inicial en la que nadie ponía en duda la preeminencia del Defensor estatal, hasta la coyuntura actual en la que se insiste más bien en una posición igualitaria.

El caso más problemático en estas relaciones serían los solapamientos. Estos menguan la eficacia de las actuaciones emprendidas y, por ende, imposibilitan el adecuado cumplimiento de los fines que persiguen estas instituciones. Ello hace que sea imprescindible ofrecer soluciones a semejantes disfuncionales duplicidades. En este sentido, el aspecto más delicado se produce en el supuesto de competencias concurrentes pues, como afirma Carro, "la supervisión de la Administración autonómica" supone "un posible conflicto o colisión de actuaciones en un mismo campo competencial ${ }^{10}$. A ello hay que sumar, en los términos que diremos infra, la Administración local. Desde un punto de vista dogmático, no resulta procedente, para enfrentar esta cuestión, acudir a la cláusula de prevalencia del Derecho estatal (art. 149.3 de la Constitución), que originaría un desplazamiento de la competencia y haría entrar al Defensor del Pueblo en lugar del autonómico. Frente a ello, el efecto que se produce, apunta Carro, "es el efecto de coordinación" de los defensores autonómicos por el Defensor del Pueblo «en los supuestos de colisión o conflicto", o "en los supuestos de coincidencia o concurrencia de actuaciones ${ }^{11}$ (a día de hoy habría que añadir, también, la idea de cooperación, por el uso conjunto y poco preciso que se hace de la coordinación y de la cooperación, aunque esta retrate mejor el tipo de relaciones institucionales ante el que estamos).

En efecto, el ámbito de la Administración autonómica puede convertirse en un ámbito competencial común del Defensor estatal (que tiene competencia universal) y el respectivo ombudsperson de esa Comunidad Autónoma. Asimismo, la Administración local es otro ámbito competencial concurrente, pues, tras ciertas dudas y discusiones iniciales, tal vez motivadas por el carácter bifronte del régimen local (STC 84/1982, FJ 4º; STC 331/1993, FJ 3º), los defensores autonómicos, en la actualidad, fiscalizan el funcionamiento de esta Administración ${ }^{12}$. En este sentido, la jurisprudencia constitucional intentó fijar

10 CARRO FERNÁNDEZ-VALMAYOR, J.L., "Las relaciones entre el Defensor del Pueblo y las figuras autonómicas afines", Revista de Estudios de la Administración Local y Autonómica, núm. 243, julio-septiembre 1989, pág. 531.

11 Ibidem, pág. 534.

12 En la normativa se usan básicamente tres fórmulas. En unos casos, se indica que las defensorías controlan la Administración local, sin ulteriores comentarios (Cataluña, Canarias — para el caso del Diputado del Común de Canarias se alude a "administraciones públicas canarias", que 
hasta dónde llega la competencia de los comisionados autonómicos respecto a los entes locales. De esta forma, la STC 142/1988, refiriéndose al Justicia de Aragón, entendió que este puede supervisar los entes locales en materias «en las que el Estatuto de Autonomía atribuya competencias a la Comunidad Autónoma de Aragón" (lo que ya decía su ley reguladora) y respecto de las que ésta haya, además, transferido o delegado en los entes locales (FJ $5^{\circ}$ ). Y la STC 157/1988 consideró constitucional el inciso del art. 2.1 de la Ley 36/1985, que habla de la supervisión de los entes locales cuando actúen en ejercicio de competencias delegadas por la Comunidad Autónoma. Por lo tanto, la postura del Tribunal Constitucional parece clara: las facultades de supervisión de las defensorías autonómicas con relación a la Administración local sólo se producen en las materias en las que el respectivo Estatuto de Autonomía otorgue competencia a la Comunidad Autónoma y respecto de las que, además, este haya transferido o delegado en los entes locales. Sin embargo, en la práctica actual, dicha doctrina jurisprudencial no se aplica pues el control que ejercen los comisionados autonómicos abarca toda la Administración local, sin distinguir el tipo de competencia que se está ejerciendo. Otra solución tendría importantes dificultades prácticas de delimitación.

La naturaleza jurídica que hemos visto antes de estas instituciones da lugar a que el Defensor del Pueblo pueda entrar en cualquier asunto con independencia de la Administración de que se trate, frente a las posibilidades de actuación de las defensorías autonómicas, que se limitan a la Administración de su propia comunidad, autonómica y local. La "Administración" que se cita en el art. 54 de la Constitución tiene un sentido genérico, pues de lo contrario, como señala Gil-Robles, "a buen seguro que se hubiese precisado" ${ }^{13}$. El art. 12.1 de la LO 3/1981, de 6 de abril, del Defensor del Pueblo, es taxativo al respecto: «El Defensor del Pueblo podrá, en todo caso, de oficio o a instancia de parte, supervisar por si mismo la actividad de la Comunidad Autónoma en el ámbito de competencias definido por esta Ley”. En la aprobación final de esta LO se desechó el intento de la proposición de ley de dejar un margen propio a los comisionados parlamentarios, delimitando las atribuciones del Defensor estatal. Entendemos que la regulación final es más acorde con la previsión constitucional y con la vigencia global de las garantías de derechos fundamentales ${ }^{14}$.

en la ley se entiende que engloba los cabildos insulares y los ayuntamientos, según el art. 17 de la Ley $7 / 2001$, del Diputado del Común-). En otros casos, se señala que las defensorías territoriales supervisan la actuación de los entes locales en las materias que les hayan sido transferidas o delegadas por la Comunidad Autónoma (Ley estatal 36/1985, Castilla-La Mancha). Y en el tercer supuesto, se alude al control de los entes locales en lo que afecta a materias sobre las cuales el Estatuto de Autonomía da competencia a la Comunidad Autónoma (Aragón, Asturias, Castilla y León, Comunidad Valenciana, Galicia, Islas Baleares, La Rioja, Navarra, Murcia). Esta última es la fórmula que parece haberse impuesto.

13 GIL-ROBLES, A., "El Defensor del Pueblo...", op. cit., pág. 38.

14 En cambio, PÉREZ CALVO, aun considerando que la interpretación del art. 12 de la LO es correcta, considera probable otra interpretación distinta "que hubiera dejado fuera del concepto de Administración que contempla el art. $54 \mathrm{CE}$ a las Administraciones de las Comunidades Au- 
Esta competencia universal del Defensor tiene ciertos problemas que impide cerrar con coherencia sus capacidades de actuación: como comisionado de las Cortes Generales sólo informa a estas, y no a los Parlamentos autonómicos ${ }^{15}$. Ello ha sido calificado por la doctrina como una "falla" ${ }^{16}$, imposible de resolver con las previsiones actuales. Sin duda, en este sentido, la labor de los defensores autonómicos, comisionados de cada parlamento territorial, puede ser más efectiva.

Al margen de la normativa que vamos a comentar en otros apartados, en la práctica, el Defensor del Pueblo deja a los comisionados autonómicos tramitar con total libertad las quejas que estos reciben referidas a su Administración autonómica y local. En cambio, el Defensor estatal sí tramita las quejas que él mismo recibe en su oficina que afectan al sector público autonómico ${ }^{17}$. Cuando recibe una queja sobre un asunto que ya está siendo tramitado por una defensoría autonómica, y le consta tal dato, se dirige a la misma para conocer el estado de tal tramitación y la resolución final. Es decir, que deja que continúe el expediente en el ombudsman autonómico pero con cierta supervisión, lo que podría dar lugar a que adopte nuevas medidas si considera insatisfactoria la resolución autonómica. Esta podría ser una manifestación práctica de la potestad de coordinación que hemos extraído dogmáticamente con anterioridad, tal vez la única existente a día de hoy. Así las cosas, los ciudadanos y ciudadanas, en este contexto competencial, pueden optar por una institución u otra, o presentar la queja en ambas.

Esta situación práctica que tenemos en la actualidad puede generar desajustes nada recomendables. Nos estamos refiriendo a la posibilidad de que recaigan dos resoluciones sobre el mismo asunto, con el fatal riesgo de que sean contradictorias, y, de no serlo, con la absurda consecuencia de pérdida de tiempo y medios a causa del solapamiento. Ello se puede producir en el ámbito de la Administración local o autonómica, que son las materias que se comparten con el Defensor estatal, dado que en la actualidad no se aplica ningún mecanismo de intercambio de información permanente que trate de

tónomas", por una razón de coherencia, relativa a que el Defensor del Pueblo sólo da cuenta de su supervisión a las Cortes Generales (PÉREZ CALVO, A., "Defensor del Pueblo y comisionado parlamentario vasco", Revista Vasca de Administración Pública, núm. 3, 1982, pág. 39). La STC 31/2010 entierra esta posibilidad, tal y como comentaremos más adelante.

15 En el proceso constituyente una enmienda en el Senado, que no tuvo éxito, presentada por el Grupo de Senadores Vascos, pretendía que el Defensor estatal actuase también como comisionado de los parlamentos autonómicos, a los que habría de informar de su labor cuando actuase en el ámbito competencial propia de la Comunidad Autónoma. También el senador OLLERO sugirió una enmienda similar, que tampoco fue acogida.

16 CARBAllo ARMAS, P., El Defensor del Pueblo. El Ombudsman en España y en el Derecho Comparado, Tecnos, Madrid, 2003, págs. 229-232. Este autor ve cómo la supervisión de todas las Administraciones públicas por parte del Defensor del Pueblo, "Sólo puede ser parcialmente continuada en las Cortes Generales".

17 Durante un tiempo ello tenía una salvedad: en el caso de Cataluña el Defensor estatal remitía al Sindic las quejas que recibía referidas a esa administración, en virtud de la reforma que en 2006 tuvo su Estatuto. Tras la STC 31/2010 esto ha dejado de suceder, y el Defensor del Pueblo ya tramita las quejas referidas a la Generalitat catalana. 
evitar esta eventualidad. Se trata de una situación criticable, que genera inseguridad jurídica y que debe ser resuelta cuanto antes con la aplicación real de fórmulas específicas de coordinación y comunicación recíproca y permanente para este tipo de problemas. Los avances tecnológicos facilitan la solución, a través, por ejemplo, de una intranet. Es deseable que cuanto antes se dé un impulso en este sentido para evitar tales desajustes.

Dejando de lado esta problemática de las competencias concurrentes y de sus posibles problemas, la importancia del tema que estamos abordando también radica en las propias discrepancias doctrinales a la hora de su análisis, que se ven alimentadas por las oscuridades de la regulación y por la evolución del propio Estado Autonómico, de la que no se puede desligar un componente politológico que oscurece el debate jurídico. Por lo tanto, aún estamos ante una cuestión en parte abierta, aunque ello pueda parecer un tanto sorprendente por el tiempo transcurrido y la trascendencia de la cuestión.

\section{LOS PRINCIPIOS DE RELACIÓN}

Las relaciones entre el Defensor del Pueblo y las defensorías autonómicas deben abordarse desde dos perspectivas: por un lado, tenemos las relaciones que marca el Derecho positivo en vigor; por otro, las relaciones fácticas que se producen por el contacto entre las diversas instituciones implicadas. Se trata, sin duda, de dos realidades diferentes, que necesitan consideraciones por separado.

\section{El PRINCIPIO DE INDEPENDENCIA O AUTONOMÍA INSTITUCIONAL}

Este principio puede considerarse un preconcepto o una precuestión en el tema de las relaciones que estamos abordando: tales relaciones no deben menguar el rasgo de independencia o autonomía que configura estas instituciones defensoras de derechos.

El art. 24.1 del Reglamento de Organización y Funcionamiento del Defensor del Pueblo alude a la autonomía que le corresponde a cada defensoría autonómica en la fiscalización de la actividad de sus respectivas administraciones. En el ámbito de las Comunidades Autónomas es particularmente claro el art. 38 de la Ley Foral 4/2000, del Defensor del Pueblo de la Comunidad Foral de Navarra, al indicar que este comisionado "es independiente y autónomo en su funcionamiento del Defensor del Pueblo designado por las Cortes Generales". También una ley de la primera época se expresa en sentido similar. Nos referimos al art. 36.1 de la Ley 3/1985, por la que se crea y regula la Institución del Ararteko: «El Ararteko es independiente y autónomo, en su funcionamiento, del Defensor del Pueblo". De una forma u otra, directa o indirecta, toda la normativa específica de las defensorías españolas parte de semejante autonomía e independencia. 
De esta situación se deriva el respeto a las funciones que cada ombudsperson ostenta y a su ejercicio, en el marco del principio de lealtad institucional, criterio clave en las relaciones entre distintas instancias territoriales (STC 239/2002, FJ 11º).

\section{LOS PRINCIPIOS DE COORDINACIÓN, COOPERACIÓN Y COLABORACIÓN}

Aparentemente, con base en el Derecho positivo en vigor, las relaciones jurídicas formalizadas entre el Defensor estatal y las defensorías autonómicas se articulan básicamente sobre estos tres principios. Sin embargo, el mal uso técnico-jurídico que la normativa hace de los mismos, confuso y sin rigor, vacía de contenido dicha afirmación. Si a ello sumamos que los acuerdos que existen para cumplir con tales principios entre el Defensor estatal y parte de los comisionados autonómicos prácticamente no se aplican, se refuerza la reflexión anterior.

Téngase en cuenta que estamos antes tres principios que, en este ámbito, no funcionan por separado, sino, por decirlo de algún modo, conjuntamente. Incluso se solapan y entrecruzan, por la misma indefinición conceptual con que los aborda la legislación. Ello, cuando menos, resulta llamativo y criticable. Es cierto que la flexibilidad que forma parte de la naturaleza de este tipo de instituciones podría englobar y permitir el uso confuso de tales principios. Sin embargo, en este caso creemos que la indefinición perjudica más que ayuda.

Se trata de unos principios que sirven para disciplinar el funcionamiento de las defensorías, pero no estamos ante criterios de reparto competencial. Como hemos dicho anteriormente, desde el punto de vista dogmático, la concurrencia competencial entre las defensorías y el Defensor del Pueblo no genera un desplazamiento competencial de aquéllas sino una coordinación de dicha concurrencia que evite disfuncionales solapamientos. Ahora añadimos, con base en ese uso confuso e intercambiable de estos tres principios, que el efecto en la práctica también puede ser la cooperación o colaboración para salvar dicha concurrencia ${ }^{18}$.

Como en parte ya se ha dicho, da la impresión que en una primera época se subrayó la idea de coordinación, y posteriormente se ha insistido en la co-

18 Estamos ante algo similar a lo que sucede con el Tribunal de Cuentas, desde este sentido amplio de coordinación que estamos empleando (el art. 29.1 de la Ley 7/1988, de 5 de abril, de Funcionamiento del Tribunal de Cuentas establece que "los órganos de control externo de las Comunidades Autónomas coordinarán su actividad con la del Tribunal de Cuentas mediante el establecimiento de criterios y técnicas comunes de fiscalización que garanticen la mayor eficacia en los resultados y eviten la duplicidad en las actuaciones fiscalizadoras"). Tampoco hay jerarquía entre el Tribunal de Cuentas estatal y los autonómicos. Doctrinalmente se defiende que aquí estamos más bien ante cooperación. Sin embargo, hay un elemento específico en este campo que no es trasladable al tema de nuestro trabajo: el campo de la jurisdicción contable, que el Tribunal de Cuentas estatal ejerce con exclusividad. 
operación. Y esto más con base en las aportaciones doctrinales que en el Derecho positivo. De todos modos, en las últimas reformas estatutarias parece perder fuerza la idea de coordinación, aunque ello es sobretodo una apreciación subjetiva antes que un dato empírico contrastable. Sea como fuere, esta aparente evolución esconde tras de sí el progresivo deseo de igualación que se ha perseguido desde algunas Comunidades Autónomas, donde se insiste, como mucho, en cooperar (y no en ser coordinados), deseo, por otra parte, que en cierto sentido choca con la interpretación constitucional considerada por nosotros más razonable, que lleva, como ya hemos visto, a cierta preeminencia del Defensor del Pueblo (lo que va unido a la coordinación). También es verdad, para complicar más este espinoso asunto, que el intento de fijar los principios de relación se hace en un período muy diferente al actual, en el que la presencia y la actividad de los comisionados autonómicos es mucho mayor. Este dato contextual juega a favor de los que abogan por posiciones igualitarias.

El principio de coordinación alude a la actividad que realiza un órgano coordinante para imponer en los entes coordinados una actuación conjunta que evite los problemas de solapamiento que para el correcto funcionamiento de las instituciones implicadas tendría la ausencia de esta coordinación ${ }^{19}$. La coordinación supone una actuación conjunta en caso de competencias concurrentes. Este concepto implica la existencia de un centro que coordina, y que hace que las actuaciones sujetas a este principio posean un fuerte componente unilateral. Sea como fuere, estamos usando un sentido un tanto lato o amplio de coordinación, que se aplica aunque no exista relación de jerarquía (recordemos que en este ámbito sólo hablamos de cierta preeminencia motivada en la ya vista relevancia constitucional ${ }^{20}$. De lo contrario habría que censurar gran parte de la regulación en este ámbito.

19 En este sentido, podemos citar la ya lejana STC 32/1983, en donde se lee: "La coordinación persigue la integración de la diversidad de las partes o subsistemas en el conjunto del sistema, evitando contradicciones y reduciendo disfunciones que, de subsistir, impedirían o dificultarían respectivamente la realidad misma del sistema" (FJ $2^{\circ}$ ). Así se evitarían "los inconvenientes de una actuación simultánea separada" (FOLCHI, I.; BAYONA, A., "La defensa de los derechos fundamentales y de las libertades públicas en al ámbito de las Comunidades Autónomas. Instituciones similares al Defensor del Pueblo, Revista Vasca de Administración Pública, núm. 6, 1983, pág. 101).

20 En un sentido estricto, la coordinación sólo se aplicaría existiendo jerarquía entre los órganos implicados, o sea, se produciría entre órganos de un mismo ente. El Derecho positivo, en España, usa ambos sentidos (por ejemplo, en la propia Constitución, en sentido amplio, el art. 154; en sentido estricto, también en la Carta Magna, los arts. 98.2 y 103.2). Por lo tanto, si se manejara sólo un sentido estricto de coordinación habría que afirmar que la normativa en vigor en el ámbito que analizamos hace un uso equivocado del mismo: en vez de coordinación debería hablar tan sólo de cooperación. El recurso a un concepto amplio de coordinación, como estamos haciendo, soslaya esta alternativa. También, como hace PÉREZ CALVO, podría diferenciarse entre la coordinación como principio que informa (en la Constitución, arts. 103.1 y 156.1) y la coordinación como competencia (art. 149.1 de la Norma Básica) (PÉREZ CALVO, A., "Actuaciones de cooperación y coordinación entre el Estado y las Comunidades Autónomas", Revista de Estudios de la Administración Local y Autonómica, núms. 235-236, 1987, pág. 478). A nosotros, ahora, sólo nos serviría el primer sentido. 
Por su parte, la cooperación hace referencia a actuaciones en un plano de igualdad en busca de un mismo fin. De ahí que, a diferencia de la coordinación, las situaciones movidas por este principio tengan un carácter primariamente bilateral o multilateral. De igual forma, la cooperación no es de aplicación sólo en competencias concurrentes sino que va más allá, afectando a competencias ajenas.

De esta forma, la idea de coordinación se acerca a la de imposición, y la de cooperación a la de voluntariedad. Por eso, esta segunda casa mejor con la reseñada autonomía e independencia.

A su vez, el principio de colaboración alude a una actuación leal entre los diversos órganos, ayudando al logro de los fines que se persiguen. Es, por lo tanto, un concepto forzosamente genérico que puede abarcar actuaciones de todo tipo, incluso preferentemente no regladas (lo que se aviene perfectamente con la naturaleza de las actuaciones de una defensoría, en gran parte aformales). No prejuzga ninguna estructura específica de relación entre los distintos entes que colaboran. En el ámbito en el que nos movemos, el de los ombudsmen, la colaboración viene justificada sobradamente por la defensa de los intereses de la ciudadanía, tanto en lo que se refiere a la protección de sus derechos como a la supervisión de la mala administración (otra actitud no tendría sentido jurídico en este ámbito).

Pues bien, estas diferencias de significación, muy sucintamente expuestas en los párrafos anteriores, no están claras en la regulación. De este modo, la normativa aplicable recoge por doquier estos tres principios, a veces por separado, a veces agrupados de diferente forma. No es posible extraer jurídicamente un sentido distinto a estas formas diferentes de recoger tales principios.

A nivel estatutario, se habla de que la defensoría autonómica ejercerá sus funciones en coordinación con el Defensor del art. 54 de la Constitución en siete estatutos, de un total de doce que prevén la figura (art. 59 del Estatuto de Aragón, art. 14.3 del Estatuto de Canarias, art. 18.3 del Estatuto de Castilla y León, art. 14 del Estatuto de Galicia, art. 51 del Estatuto de las Islas Baleares, art. 22 del Estatuto de La Rioja, y art. 15 del Estatuto del País Vasco). A la colaboración se refieren el art. 128.3 del Estatuto de Andalucía, el art. 18.3 del Estatuto de Castilla y León, y el art. 78.2 del Estatuto de Cataluña. En cambio, los estatutos no aluden a la cooperación en este ámbito.

La $L O 3 / 1981$, del Defensor del Pueblo, en su art. 12.2, se refiere a la coordinación y a la cooperación. En este caso sí parece que ha habido intención de usar ambos principios en un sentido diferente: «los órganos similares de las Comunidades Autónomas coordinarán sus funciones con las del Defensor del Pueblo y este podrá solicitar su cooperación". Y ello "a los efectos previstos en el párrafo anterior" (es decir, en lo relativo a la supervisión por el órgano estatal de la actividad de la Comunidad Autónoma —art. 12.1-). O sea, que la coordinación y la cooperación, según la normativa reguladora del Defensor estatal, sólo procede en ese ámbito concurrente de la Administración autonómica (como por otra parte, ya dimos a entender en la construc- 
ción dogmática antes efectuada). Esta ley quiere dar un sentido de obligación a la coordinación que está muy alejado de la realidad del verdadero funcionamiento interinstitucional. Sobre ello volvemos de inmediato.

El Reglamento de Organización y Funcionamiento del Defensor del Pueblo, de $1983^{21}$, parece, incluso, que intenta ir más allá en su art. 24.1 al indicar que el Defensor del Pueblo «ejercerá la alta coordinación entre sus propias competencias y las atribuidas a los órganos similares que puedan constituirse en las Comunidades Autónomas, sin perjuicio de la autonomía que les corresponda en la fiscalización de la actividad de las respectivas Administraciones autonómicas". Por un lado, y como ya defendimos, al no haber jerarquía la autonomía se mantiene, apareciendo la coordinación en posibles solapamientos. Pero por otro, el ejercicio de la alta coordinación sí es una expresión que teóricamente permite defender que tal coordinación puede ser impuesta por el Defensor estatal, habido cuenta su preeminencia, no siendo, por lo tanto, voluntaria. O sea, que podría imponer acciones conjuntas a los defensores en actuaciones coincidentes.

Sin embargo, en la práctica no hay ningún tipo de imposición forzosa sino que la forma en que se desarrolla tal coordinación (o mera relación entre instituciones) es voluntaria. La evolución no ha seguido las criticables previsiones del Reglamento. Esta situación se explicaría tanto por la imprecisión conceptual señalada como por la naturaleza misma de los citados artículos 12.2 de la LO 3/1989 y 24.1 del Reglamento: son normas de conflicto, que como tales sólo se aplican en coincidencia de actuaciones, no de forma general, previa y continua. Doctrinalmente se ha negado que exista en manos del Defensor estatal una competencia de coordinación general ${ }^{22}$. No estamos, por lo tanto, ante una competencia de coordinación en manos del Defensor estatal sino ante un mecanismo de solución de concretos conflictos, que, en la práctica, no parece que se pueda sustanciar sin acuerdo de voluntades. Al no ser una competencia como tal, no desplaza las funciones del defensor autonómico. De ahí que sea una figura jurídica diferente, por ejemplo, a la coor-

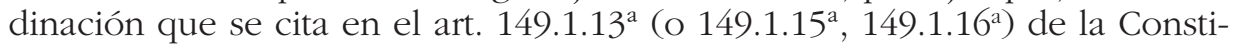
tución, que sí aparece como una competencia técnicamente hablando (en este supuesto, en manos del Estado central y de carácter general).

21 EMBID IRUJO ha puesto de relieve la improcedencia de una norma de esta naturaleza para "producir efectos frente a sujetos externos a la misma organización parlamentaria de las Cortes Generales, como los comisionados autonómicos (EMBID IRUJO, A., El control de la Administración Pública por los comisionados parlamentarios autonómicos, Ministerio para las Administraciones Públicas, 2. ${ }^{a}$ ed., Madrid, 1991, pág. 83)

22 Por ejemplo, EMBID IRUJO, A., El control de la Administración Pública..., op. cit., págs. 80-81. Lo que sí puede entenderse es que existe otra coordinación, la que aparece en los concretos supuestos de solapamiento ante la tramitación de las quejas autonómicas (en este sentido, CARRO FERNÁNDEZ-VALMAYOR, J.L., "Las relaciones...”, op. cit., págs.. 536-537). Esto es lo que se produciría en el caso comentado en el epígrafe anterior de una queja ya existente en el ombudsperson autonómico que llega con posterioridad también al Defensor del Pueblo, y este se dirige a aquel. Esta actuación sería un ejemplo de coordinación en determinado caso. 
A su vez, el art. 24.2 Reglamento de Organización y Funcionamiento del Defensor del Pueblo establece una previsión que habilita el recurso a la colaboración en todo caso: "En el ejercicio de sus propias competencias, el Defensor del Pueblo podrá solicitar la colaboración y auxilio de los órganos similares de las Comunidades Autónomas".

Con el confesado objetivo de dotarse de de normas adecuadas que "desarrollen y concreten el modo de aplicación de los principios básicos de coordinación y cooperación previstos en el art. 12.2" de la LO 3/1981, se aprueba la Ley 36/1985, de 3 de noviembre, por el que se regulan las relaciones entre la Institución del Defensor del Pueblo y las figuras similares en las distintas Comunidades Autónomas. La cita procede se su Exposición de Motivos. Pero pese a estos deseos de precisión, el resultado final no presenta tal carácter, sobre todo por el uso indistinto y un tanto confuso que se hace de coordinación, cooperación y colaboración. De esta forma, el art. 2 se rotula "Régimen de colaboración y coordinación de las instituciones". Su apartado 1 prevé que la supervisión de la Administración autonómica y local ${ }^{23}$ se podrá realizar "por el Defensor del Pueblo y el comisionado parlamentario autonómico en régimen de cooperación, según lo establecido en el apartado segundo de este artículo" (pero el apartado siguiente habla de coordinación y colaboración... ¿está el legislador usando estos conceptos de manera indistinta?). A continuación, se indica que ello tendrá lugar «en todo aquello que afecte a materias sobre las cuales se atribuyan competencias a la Comunidad Autónoma". Se trata, simplemente, de abrir la posibilidad de acuerdos a la hora de controlar la Administración local y autonómica. La finalidad última de los mismos es de suponer que radica en la búsqueda de una mayor eficiencia evitando solapamientos. Esta previsión permite que las quejas de este ámbito autonómico y local puedan recaer fundamentalmente en los ombudspersons territoriales, aunque ello sin cerrar la posible actuación del Defensor estatal. En efecto, la parte final de dicho art. 2.1 de la Ley 36/1985 establece que no se menguan las facultades del Defensor del Pueblo establecidas en la Constitución y en su Ley Orgánica. Esta semeja una previsión innecesaria, que tal vez trata de dejar bien claro que el Defensor estatal no pierde por mor de ningún acuerdo entre las defensorías su competencia general en todo el territorio, incluida las Administraciones autonómicas. Recordemos que el art. 24.3 del Reglamento prohíbe al Defensor del Pueblo delegar en sus similares autonómicos la competencia que le otorga el art. 54 de la Constitución de defensa de los derechos del Título I.

Acto seguido, el art. 2.2 de esta Ley 36/1985 establece, en primer lugar, que "a fin de desarrollar y concretar adecuadamente la colaboración y coordinación entre el Defensor del Pueblo y los comisionados parlamentarios au-

23 Respecto a los entes locales, "cuando actúen en ejercicio de competencias delegadas por la Comunidad Autónoman. Esta restricción en el ámbito local la ha criticado, por ejemplo, EMBID IRUJO en El control de la Administración Pública..., op. cit., págs. 116 y ss. En la práctica, como ya se apuntó, tal restricción no se aplica. 
tonómicos, se concertarán entre ellos acuerdos”. Tras lo cual se señala el contenido de dichos acuerdos, que abarca cinco temas: los ámbitos de actuación de las Administraciones públicas objeto de supervisión, los supuestos de actuación de las defensorías autonómicas, sus facultades, el procedimiento de comunicación entre el Defensor estatal y estas defensorías, y la duración de los propios acuerdos. De nuevo estamos ante una previsión vaga y genérica, con un contenido que no aporta mucho por su propia indefinición. Carballo Armas considera que, "en síntesis, lo que es establece no es otra cosa que un esquema de mínimos ${ }^{24}$. Su ámbito se puede referir, por tanto, a la Administración autonómica y local (la remisión del apartado 1 lleva a ello), y a la Administración del Estado central (se supone que la periférica). Así las cosas, con estos acuerdos, las defensorías autonómicas podrían entrar en un marco competencial del Defensor del Pueblo al que en principio no tienen acceso, si bien el Defensor estatal no podría desaparecer: de nuevo hay que recordar el art. 24.3 del Reglamento del Defensor del Pueblo, aunque la propia previsión constitucional del art. 54 también vetaría un total desapoderamiento competencial. Ello, como indica Carro, sería "Contradictorio con el mismo concepto de colaboración ${ }^{25}$. Al margen de esto, lo que sí está claro es que, al ser acuerdo, se necesita la confluencia de voluntades, no siendo posible la imposición unilateral.

Ante la falta de acuerdo se aplicaría lo dispuesto en el art. 2.3 de esta Ley 36/1985, que permite al Defensor, «en la supervisión de la actividad de órganos de la Administración Pública estatal, que radiquen en el territorio de cada Comunidad Autónoma", "recabar la colaboración de respectivo comisionado parlamentario para la mejor eficacia de sus gestiones y recibirá de él las quejas que le hubieren sido remitidas sobre la actividad de dichos órganos de la Administración pública estatal". Se trata de una previsión en cierto sentido redundante pues esta colaboración ya está prevista en el art. 24.2 del Reglamento de Organización y Funcionamiento del Defensor del Pueblo, y se infiere del art. 12.2 de su Ley Orgánica. Esta "colaboración" parece que no es otra cosa más que "cooperación". Además, se establece que el Defensor del Pueblo recibirá de las defensorías las quejas que se les remitan sobre esta Administración estatal periférica. De igual forma, se alude a que «el Defensor del Pueblo podrá informar al comisionado parlamentario del resultado de sus gestiones".

Así las cosas, el desarrollo que ofrece esta Ley 36/1985 a la LO 3/1981 se puede tildar, ciertamente, de parco y poco nítido, aunque hay que decir en

24 CARBAllo ARMAS, P., El Defensor del Pueblo..., op. cit., pág. 209.

25 CARRO FERNÁNDEZ-VALMAYOR, J.L, "Las relaciones...", op. cit., pág. 540. Este autor indica que en estos acuerdos, al menos, habrá que prever "una supervisión final" del Defensor estatal sobre lo actuado por los defensores autonómicos (pág. 541). En cambio, EMBID ha afirmado que la virtualidad de los acuerdos de la Ley 35/1985 se limita a la Administración autonómica y local, no abarcando, por lo tanto, la Administración periférica del Estado (EMBID IRUJO, A., El control de la Administración..., op. cit., pág. 114). 
descargo de la misma que responde a un período iniciático, que trataba de ofrecer un marco de referencia al desarrollo de las defensorías autonómicas. Por lo tanto, hay que reputarla, en parte, un tanto superada. La doctrina también ha criticado la ley de 1985, subrayando su vaguedad ${ }^{26}$, el uso confuso e indistinto de los términos cooperación y coordinación ${ }^{27}$, y la falta de claridad suficiente para articular los ámbitos de actuación de cada institución ${ }^{28}$.

Las leyes autonómicas aluden a estos principios, en general con esa imprecisión que ya señalamos: coordinación con el Defensor del Pueblo ${ }^{29}$; cooperación ${ }^{30}$, que en la actualidad puede verse como la idea con mayor predicamento en sede autonómica (por las ya comentadas connotaciones igualitarias); y colaboración ${ }^{31}$.

Tras este rápido recorrido, se impone una breve recapitulación de este poliédrico apartado. Como acabamos de ver, el uso que se hace de estos tres principios es confuso y poco riguroso desde el punto de vista técnico-jurídico, por lo que ofrecen pocas posibilidades para fijar con claridad la marcha de las relaciones estudiadas. Tanto la legislación estatal como la autonómica recurren a ellos pero no con la claridad dogmática necesaria, por lo que semeja que lo más oportuno para no entrar en contradicciones es usar los tres principios

26 GARRIDO LÓPEZ, C., "Fundamento y virtualidad de los acuerdos de cooperación entre el Defensor del Pueblo y los comisionados parlamentarios autonómicos", en APARICIO PÉREZ, M.A. (coord.), Derechos constitucionales y formas políticas, Cedecs, Barcelona, 2001, pág. 606; RAZQUIN LIZARRAGA, J.A., "Las relaciones con el Defensor del Pueblo de las Cortes Generales y otras instituciones análogas", en PÉREZ CALVO, A. (Dir.), El Defensor del Pueblo de Navarra, Gobierno de Navarra, 2009, pág. 311.

27 CARBallo ARMAS, P., El Defensor del Pueblo..., op. cit., pág. 211.

28 LÓPEZ BASGUREN, A., "Las relaciones entre el Defensor del Pueblo y las figuras similares de las Comunidades Autónomas. Su regulación en la Ley 36/1985", Revista Vasca de Administración Pública, núm. 14, 1986, pág. 256.

29 Arts. 1.2 y 13 de la Ley 9/1983, del Defensor del Pueblo Andaluz; art. 6.1 de la Ley 4/1985, del Justicia de Aragón; art. 36.1 de la Ley 5/2005, del Procurador General del Principado de Asturias; art. 18 de la Ley 7/2001, del Diputado del Común de Canarias; art. 4. de la Ley 2/1994, del Procurador del Común de Castilla y León; art. 1.5 de la Ley 16/2001, del Defensor del Pueblo de Castilla-La Mancha; art. 1.2 de la Ley 11/1988, del Sindic de Greuges de la Comunidad Valenciana; arts. 16.3 y 26.2 de la Ley 6/1984, del Valedor do Pobo; art. 5.1 de la Ley 1/1993, del Sindic de Grenges de las Islas Baleares; art. 6.1 de la Ley 6/2006, del Defensor del Pueblo Riojano; art. 1.2 de la Ley Foral 4/2000, del Defensor del Pueblo de la Comunidad Foral de Navarra; art. 9.3 de la Ley 3/1985, por la que se crea y regula la Institución del Ararteko; art. 37.1 de la Ley 6/2008, del Defensor del Pueblo de la Región de Murcia.

30 Arts. 1.2 y 13 de la Ley 9/1983, del Defensor del Pueblo Andaluz; art. 6.1 de la Ley 4/1985, del Justicia de Aragón; art. 1.5 de la Ley 16/2001, del Defensor del Pueblo de Castilla-La Mancha; art. 4. de la Ley 2/1994, del Procurador del Común de Castilla y León; art. 5.1 de la Ley1/1993, del Sindic de Greuges de las Islas Baleares; art. 1.2 de la Ley 11/1988, del Sindic de Grenges de la Comunidad Valenciana; art. 16.3 y 26.2 de la Ley 6/1984, del Valedor do Pobo; art. 6.1 de la Ley 6/2006, del Defensor del Pueblo Riojano; art. 1.2 de la Ley Foral 4/2000, del Defensor del Pueblo de la Comunidad Foral de Navarra; art. 37.1 de la Ley 6/2008, del Defensor del Pueblo de la Región de Murcia.

31 Art. 36.1 de la Ley 5/2005, del Procurador General del Principado de Asturias; art. 1.5 de la Ley 16/2001, del Defensor del Pueblo de Castilla-La Mancha; art. 78 de la Ley 24/2009, del Sindic de Greuges de Cataluña; art. 16.3 de la Ley 6/1984, del Valedor do Pobo. 
conjuntamente. Como indica Díez Bueso, la normativa "no solucionó el problema del solapamiento de actuaciones derivado de la concurrencia competencial ${ }^{32}$, con lo que el problema de raíz sigue presente en toda su extensión. En fin, sentencia Bermejo Vera que "no puede dejar de extrañar el planteamiento de los principios de coordinación y cooperación en la normativa (...) ya que de por sí es difícil atribuir carácter jurídico a la técnicas de coordinación y cooperación, semejante planteamiento ha sido adoptado irreflexivamente o cuando menos, sin haber tenido en cuenta los problemas que la ejecución de tales principios podría provocar, ${ }^{33}$.

Lo que al menos está claro, en cambio, es que tales principios obligan a un contacto continuo entre estas instituciones que permita mejorar su funcionamiento y maximice la garantía de los derechos de la ciudadanía, ofreciendo un conjunto de posibilidades de actuación amplio. Unas posibilidades que en la actualidad se encuentran, en parte, desaprovechadas.

\section{Solicitud DE ACTUACión}

Bajo este enunciado de "solicitud de actuación" queremos aludir a una específica forma de relación que tiene la suficiente individualidad para no estar subsumida en otros principios, aunque podría entrar en el terreno de la colaboración.

Este mecanismo de relación se concreta en la posibilidad que tienen los comisionados autonómicos de dirigirse al Defensor del Pueblo para solicitar que presente un recurso de amparo o un recurso de inconstitucionalidad ante el Tribunal Constitucional. Este Defensor es libre, obviamente, para su presentación o no, es decir, que la remisión es para su conocimiento y consideración.

En este sentido, tenemos el art. 26 de la Ley 9/1983, del Defensor del Pueblo Andaluz; los arts. 23 y 27.4 de la Ley 4/1985, del Justicia de Aragón; el art. 21 de la Ley $7 / 2001$, del Diputado del Común de Canarias; los arts. 22 y 24.4 de la Ley 2/1994, del Procurador del Común de Castilla y León; el art. 30.3 de la Ley 16/2001, del Defensor del Pueblo de Castilla-La Mancha; el art. 39 de la Ley 6/1984, del Valedor do Pobo; el art. 25 de la Ley 1/1993, del Sindic de Greuges de las Islas Canarias; el art. 29.4 de la Ley 6/2006, del Defensor del Pueblo Riojano; el art. 39 Ley Foral 4/2000, del Defensor del Pueblo de la Comunidad Foral de Navarra; el art. 37 de la Ley 3/1985, por la que se crea y regula la Institución del Ararteko; y el art. 33.4 y 33.5 de la Ley 6/2008, del Defensor del Pueblo de la Región de Murcia.

32 DÍEZ BUESO, L., Los defensores del pueblo (ombudsmen) de las Comunidades Autónomas, Departamento de Publicaciones del Senado, Madrid, 1999, pág. 206.

33 BERMEJO VERA, J., "El Defensor del Pueblo y las figuras similares autonómicas: alcance de la coordinación y cooperación", Revista Española de Derecho Administrativo, núm. 68, 1990, pág. 526. 
Esta posibilidad de comunicación suele estar conectada con la competencia de los comisionados autonómicos de tutela del ordenamiento jurídico propio de la Comunidad Autónoma y de su Estatuto de Autonomía (Aragón, Castilla y León, Castilla-La Mancha, La Rioja). No deja de ser una competencia ajena a la naturaleza del Ombudsman, cuya explicación hay que encontrarla en la propia dinámica del Estado Autonómico.

A veces la previsión es más genérica y abierta, con cierto componente enigmático, pues alude a que el Ombudsman autonómico le puede sugerir «la medida a adoptar" al Defensor cuando haya una violación del Estatuto derivada de un acto del parlamento territorial ${ }^{34}$.

\section{El auXilio mutuo}

Asimismo, la normativa reguladora alude a un principio de auxilio mutuo que regula las relaciones objeto de este trabajo. Ello es una concretización de la genérica idea de colaboración y de la lealtad institucional, que viene impuesta por la relevancia de las funciones asumidas y por el mayor valor de los derechos fundamentales. La citamos por separado para ganar claridad expositiva.

De esta forma, el art. 24.2 del Reglamento del Defensor del Pueblo se establece que este podrá solicitar "el auxilio de los órganos similares de las Comunidades Autónomas". Al margen de ello, este deber de recíproco apoyo y lealtad mutua se halla ínsito en el sistema autonómico (STC 64/1990, FJ $7^{\circ}$ ).

Se trataría de un deber de asistencia recíproca, de perfiles difusos (en correspondencia con la flexibilidad de las actuaciones de este tipo de entes), que se activaría cuando la necesidad llevase a ello, y que se podría concretar en recibir el apoyo de medios materiales o personales. Su concreción radicaría precisamente en esta puesta a disposición de medios para el ejercicio de ciertas funciones, en búsqueda de una articulación razonable de las mismas.

\section{LAS RELACIONES PERSONALES}

Para conocer la verdadera trascendencia de las relaciones entre el Defensor del Pueblo y las defensorías autonómicas hay que ir más allá de la regulación del Derecho Positivo y buscar otros elementos explicativos. En este sentido, cobra singular relieve el talante personal de los titulares de dichas instituciones, que hará la relación más fluida o la obstaculizará.

No cabe duda, la propia flexibilidad inherente al funcionamiento de un Ombudsman y la falta de precisión de la normativa reguladora a la hora de fijar los principios de relación (como acabamos de ver), subraya la importancia de las relaciones personales entre los miembros de estas instituciones. La ma-

34 Art. 28 de la Ley 4/1985, del Justicia de Aragón; art. 25 de la Ley 2/1994, del Procurador del Común de Castilla y León. 
nera en que se desenvuelva este trato personal, sobre todo en lo que respecta a los titulares, hará que la forma de colaboración o cooperación sea una u otra. Por lo tanto, las relaciones que hoy en día tienen lugar entre los comisionados parlamentarios están muy supeditadas a esta variable de las relaciones personales.

De este modo, entramos en un terreno sociológico difícil de analizar jurídicamente, por lo que estimamos que lo dicho es suficiente para el presente artículo, insistiendo, de nuevo, en la importancia de la cuestión: la dinámica real de estas relaciones se basa en gran medida en las relaciones personales, tanto entre los titulares de estas instituciones como entre el personal al servicio de las mismas. Ello determinará, a la postre, su fluidez e intensidad.

\section{MANIFESTACIONES DE TALES RELACIONES}

Las relaciones analizadas tienen reflejo en un elevado número de manifestaciones, de diversa índole y extensión. Ello prueba la complejidad del tema y lo cercanas que caminan estas instituciones en diversos aspectos. En los siguientes cinco subapartados intentamos condensar estas manifestaciones. Téngase en cuenta que no es una lista cerrada, sólo ejemplificativa para no extendernos demasiado. Dejamos fuera, por ejemplo, las solicitudes de actuación (a las que ya nos referimos desde el punto de vista de los principios de regulación) y las modalidades de intercambio de información (en parte desactivadas, en parte aformales). Recordemos que en la introducción avisábamos que sólo perseguíamos reflexionar sobre los ejes básicos de esta problemática, no agotarla ${ }^{35}$.

\section{ACUERDOS O CONVENIOS BILATERALES DE COOPERACIÓN Y COLABORACIÓN}

Tal vez la manifestación más evidente de estas relaciones entre el Defensor del Pueblo y los comisionados autonómicos sea la posibilidad de celebrar acuerdos bilaterales, que podrían catalogarse de cooperación y colaboración. El art. 2.2 de la Ley 36/1985 alude expresamente a ellos con el contenido que ya recogimos más arriba. En la normativa que regula las defensorías territoriales también se prevén ${ }^{36}$. El Defensor del Pueblo ha firmado

35 Si se quiere completar la visión de estos instrumentos, desde el punto de vista de una defensoría, puede verse RAZQUIN LIZARRAGA, J.A., "Las relaciones...", op. cit., págs. 328 y ss.

36 Art. 6.2 de la Ley 4/1985, del Justicia de Aragón; art. 36.3 de la Ley 5/2005, del Procurador General del Principado de Asturias; art. 4.1 de la Ley del Procurador del Común de Castilla y León; art. 78.3 de la Ley 24/2009, del Sindic de Greuges de Cataluña; art. 38.2 de la Ley 6/1984, del Valedor do Pobo; art. 5.2 de la Ley 1/1993, del Sindic de Grenges de las Islas Baleares; art. 6.1 de la Ley 6/2006, del Defensor del Pueblo Riojano; art. 38.2 de la Ley Foral 4/2000, del Defensor del Pueblo de la Comunidad Foral de Navarra; art. 36.2 de la Ley 3/1985, por la que se crea y regula la Institución del Ararteko; art. 37 de la Ley 6/2008, del Defensor del Pueblo de la Región de Murcia. 
este tipo de convenios en diversas ocasiones, las más recientes con la Defensora del Pueblo Riojano (el 23 de febrero de 2007), con la Procuradora General del Principado de Asturias (el 27 de febrero de 2007), y con el Defensor del Pueblo de la Región de Murcia (el 1 de junio de 2009).

Sin embargo, pese a esta importancia teórica en el terreno de las relaciones recíprocas, pues permiten detallar con precisión las relaciones recíprocas, los convenios de colaboración existentes prácticamente no se aplican. Podría decirse que están en gran parte superados por la dinámica personal de las instituciones. Tal vez por ello se está generando el estado opinión sobre la necesidad de actualizar y modernizar los convenios, aunque el punto de partida para su reformulación debería ser más bien la efectividad, o sea, que contuvieran cláusulas que se aplicaran de verdad y que realmente sirvieran para la mejora de las garantías que se ofrecen a la ciudadanía ${ }^{37}$.

La estructura de estos acuerdos se repite: tras una introducción en la que el Defensor estatal y el autonómico reafirman su voluntad de concretar el marco de colaboración entre ambas instituciones, hay una parte dedicada a la cooperación (con 6 artículos: principios de relación, supervisión de los órganos periféricos de la Administración Pública del Estado, supervisión de la Administración de la Comunidad Autónoma, supervisión de las Administraciones locales, colaboración del comisionado autonómico en las actuaciones del Defensor de estatal en su Comunidad, y otras formas de colaboración), y otra relativa a la coordinación (con un artículo que recoge lo que denomina "técnicas de coordinación formal» —reuniones, comunicaciones y coordinación de sus sistemas informáticos-).

La articulación de un mecanismo nacional de prevención de la tortura, derivado del Protocolo de Naciones Unidas de 2002, podría constituir un uso más en este ámbito, si bien está por el momento pendiente de realización.

\section{JORNADAS DE COORDINACIÓN DE DEFENSORES DEL PUEBLO 38}

Se trata de una actividad de carácter anual muy consolidada, como lo prueba que en septiembre de 2010, ha tenido lugar en Logroño, la edición $\mathrm{XXV}$. A las mismas asisten siempre el Defensor estatal y todas las defensorías autonómicas. A medida en que su número ha ido creciendo, los participantes

37 También existe un convenio multilateral de "colaboración entre las instituciones autonómicas de defensores del pueblo", firmado en Albacete el 22 de octubre de 2003 por los ombudsmen de Andalucía, Aragón, Canarias, Castilla y León, Castilla-La Mancha, Cataluña, Comunidad Valenciana, Galicia, Navarra y País Vasco. En la actualidad también puede afirmarse que dicho convenio tampoco se aplica.

38 Ya en 1980, FAIRÉN GUILLÉN, ante el riesgo que detectaba de contradicciones entre las recomendaciones del Defensor a escala nacional y los regionales o municipales, consideraba "un elemento fundamental" las reuniones periódicas "para cambiar impresiones y acordar unificaciones de decisiones sobre quejas que tienen la misma base" (FAIRÉN GUILLEN, V., "¿Posibilidad y conveniencia de introducir a los "Ombudsmännen" en los ordenamientos jurídicos de naciones de habla ibérica“, Revista de Estudios Políticos, núm. 14, 1980, pág. 46). 
de las jornadas también. Por lo general, la realización de cada jornada exige un trabajo preparatorio previo que se dilata bastante en el tiempo, con varias reuniones y desarrollo de talleres temáticos que sirven de base para la discusión posterior de las conclusiones.

Esta dilatada existencia hace que los temas que ya han sido abordados en las mismas sean ciertamente muy numerosos (algunos repitiéndose en distintas jornadas), por ejemplo: menores, salud mental, medio ambiente urbano, tolerancia, pedagogía de la comunicación de los Ombudsmen, el funcionario público como reclamante, control de la Administración local, educación para la paz, la mujer como reclamante, solución convencional de conflictos, extranjería, exclusión social, residuos y vertederos como problema medioambiental, mediación familiar, protección del patrimonio cultural, personas mayores, desarrollo sostenible, penas alternativas a la prisión, responsabilidad patrimonial de la Administración, nuevas tecnologías, servicios sociales, acceso a la vivienda, violencia contra las mujeres, servicios para la infancia, Administración de justicia y menores, urbanismo y medioambiente, personas en situación de desprotección social grave. La última edición analizó el impacto de la crisis económica. Sorprende, sin embargo, que no se hayan estudiado de forma directa y monográfica las relaciones que dan título a este trabajo. En esta línea se expresa Díez Bueso, al señalar que las jornadas "no han procurado el establecimiento de fórmulas de colaboración, sino que se han ocupado del análisis de los temas más abordados por estas instituciones" ${ }^{39}$.

En las actas de dichas jornadas se pueden leer, en las palabras de presentación, de bienvenida o de apertura, afirmaciones que enfatizan la importancia de construir una relación fluida. De esta forma, por ejemplo, en la edición VIII (Madrid, 1993) se manifiesta el deseo de "continuar y profundizar en las relaciones de cooperación y coordinación"; en la edición XI (León, 1996, pág. 14) se alude a la "colaboración, voluntad de entendimiento y el deseo de acercamiento entre las distintas instituciones aquí representadas"; en la edición XVI (Madrid, 2001, pág. 20) el propio Defensor del Pueblo indica que "en estos tiempos que corren, si cabe más que nunca, se hacen necesarias las relaciones de coordinación entre las instituciones de vigilancia y defensa de los derechos humanos, ante la complejidad creciente de las tareas que tenemos encomendadas, inmersos como estamos en un mundo globalizado e interconectado"; en la edición XXIII (Asturias, 2008, pág. 19) el Defensor estatal, de nuevo, alaba a las jornadas al tildarlas de "dinámicas, rigurosas, enriquecedoras y, sobre todo, propiciadoras de un clima de entendimiento que supera la simple cumplimentación de lo recomendado por la norma básica de coordinación (...) es en estas jornadas de coordinación donde se dinamizan los esfuerzos para aunar nuestro quehacer. Esta confluencia de voluntades no llega todo lo lejos que se desea, sobre todo por la deficiente regulación.

También en las conclusiones de las jornadas a veces se encuentran afirmaciones en una línea similar. De esta forma, en las conclusiones de la edi-

39 DÍEZ BUESO, L., Los defensores del pueblo..., op. cit., pág. 208. 
ción XIII (Canarias, 1998) se establece que "en la línea de profundizar en la coordinación y colaboración entre las distintas instituciones (lo que constituye el objetivo de estas jornadas) se constata la necesidad de ejercitar el conjunto de facultades que el ordenamiento jurídico otorga a los defensores del pueblo, al objeto de alcanzar el más alto grado de eficacia en el desempeño de las funciones de control que tienen atribuidas"; en las conclusiones de las Jornadas XVI (Madrid, 2001), al referirse a la inmigración, se constata que "las medidas de cooperación, de planificación y de intercambio de experiencias pueden resultar muy útiles para la gestión de la actividad ordinaria de los defensores".

Asimismo, a veces alguna defensoría organiza otro tipo de jornadas con motivo de cierto acontecimiento especial, como el aniversario de su creación. Sirve de ejemplo, las Jornadas realizadas el 22 y 23 de junio de 2009, en Santiago de Compostela, con motivo del XXV Aniversario de la creación del Valedor do Pobo "Creando un espacio para la defensa de los derechos: 25 años de la Ley 6/1984, del Valedor do Pobo".

\section{QueJAS REMITIDAS}

Como consecuencia de este sistema de relaciones que estamos viendo, una importante manifestación práctica del mismo es el reenvío de quejas. Lo habitual es la remisión en un solo sentido: las quejas sobre la Administración periférica del Estado central, que reciben los comisionados autonómicos, se remiten al Defensor del Pueblo. Ello es una consecuencia del principio de cooperación. Esta remisión debe ser comunicada al autor de la queja porque de lo contrario esa falta de información le podría perjudicar sus intereses.

Como ya se vio, el art. 2.3 de la Ley 36/1985 prevé que los ombudsmen territoriales remitan al Defensor del Pueblo las quejas que reciban sobre la actividad de la Administración periférica del Estado radica en su territorio ${ }^{40}$. Asimismo, parte de la normativa específica de las defensorías autonómicas alude a este traslado de quejas ${ }^{41}$.

De este modo, esta remisión por parte de los comisionados parlamentarios autonómicos ha sido habitual ${ }^{42}$, y en ocasiones numerosa. Sus fluctuaciones dificultan encontrar un patrón explicativo. Por lo que respecta al presente siglo, los datos son los siguientes: 2001 (1646), 2002 (1435), 2003

40 Un supuesto diferente, aunque con cierto sentido similar, es la previsión del art. 1.2.c) de esta Ley 36/1985: los comisionados autonómicos notificarán al Defensor del Pueblo las infracciones que observen en las actividades de las Administraciones no autonómicas.

41 Art. 6.3 de la Ley 4/1985, del Justicia de Aragón; art. 4.2 de la Ley del Procurador del Común de Castilla y León; art. 38.3 de la Ley 6/1984, del Valedor do Pobo; art. 5.3 de la Ley 1/1993, del Sindic de Greuges de las Islas Baleares; art. 6.2 de la Ley 6/2006, del Defensor del Pueblo Riojano; art. 37.2 de la Ley 6/2008, del Defensor del Pueblo de la Región de Murcia.

42 Aunque hay algún caso que impide hablar en este punto de uniformidad. Vid., al respecto, DÍEZ BUESO, L., Los defensores del pueblo..., op. cit., págs. 211 y ss. 
(1558), 2004 (1684), 2005 (2011), 2006 (1678), 2007 (1554), 2008 (2263), 2009 (1976). Y por lo que respecta al porcentaje que las quejas remitidas representan del total de quejas recibidas por el Defensor del Pueblo: $2001(12,5)$, 2002 (6,82), 2003 (9,05), 2004 (11,71), 2005 (5,08), 2006 (5,36), 2007 (9,02), $2008(9,57), 2009(8,97)$.

La remisión en sentido inverso, es decir, del Defensor del Pueblo a la defensoría autonómica, no se produce. La competencia general del Defensor estatal permite que ello sea así, aunque podría existir un acuerdo en otro sentido (al amparo del ya citado art. 2.2 de la Ley 36/1985).

\section{VISITAS}

Igualmente, forman parte de la normalidad institucional las visitas recíprocas que tienen lugar entre del Defensor estatal y los comisionados parlamentarios autonómicos. El talante personal de los implicados, que ya defendimos como elemento clave en estas relaciones, incide aquí poderosamente.

Un examen de los informes ordinarios de los diversos ombudspersons permite ver cada año cómo se producen tales visitas. Para no aburrir al lector, sólo aludimos al último año, el 2009: 11 de febrero, visita del Defensor del Pueblo de la Región de Murcia a la sede del Defensor estatal; 27 de abril, visita del Sindic de Grenges de la Comunidad Valenciana y de su Adjunto Segundo; y 13 de mayo, visita del Valedor do Pobo.

\section{REUNIONES PROTOCOLARIAS}

Finalmente, nos referimos a lo que hemos llamado reuniones protocolarias, es decir, motivadas por algún acto que objetivamente lleva a la conveniencia de su realización, es decir, diferentes a visitas y reuniones de índole subjetiva y, a veces, informal.

En este sentido, tenemos la asistencia a tomas de posesión y despedidas, que suelen congregar a la casi la totalidad de los ombudspersons españoles. También sería el caso de la firma de algún convenio. De nuevo, la consulta a los informes ordinarios de las instituciones sirve para comprobar que estamos ante una práctica habitual. Como en el caso anterior, sólo ponemos ejemplos del pasado 2009: 6 de marzo, asistencia del Defensor del Pueblo y su Adjunto Segundo a la toma de posesión del Sindic de Greuges de la Comunidad Valenciana; 27 de marzo, asistencia de la Secretaria General del Defensor del Pueblo a los actos organizados con motivo del XXV aniversario de la Ley del Sindic de Greuges de Cataluña; 1 de junio, firma en Cartagena del Convenio de cooperación y coordinación entre el Defensor del Pueblo y el Defensor del Pueblo de la Región de Murcia; y 17 de junio, asistencia en Vitoria del Defensor del Pueblo y de su Adjunto Segundo al 20 Aniversario del Ararteko. 


\section{EL CASO DEL ESTATUTO DE CATALUÑA}

La reciente STC 31/2010, que resuelve el recurso de inconstitucionalidad contra la LO 6/1006, de 19 de julio, de reforma del Estatuto de Autonomía de Cataluña, obliga a efectuar alguna reflexión en el marco del tema que estamos abordando.

El art. 78.1 de dicho texto, en su versión inicial, establecía que "el Síndic de Greuges tiene la función de proteger y defender los derechos y las libertades reconocidos por la Constitución y el presente Estatutom. Tras ello añadía: "A tal fin supervisa, con carácter exclusivo, la actividad de la Administración de la Generalitat".

Pues bien, la Sentencia del Alto Tribunal declara inconstitucional el inciso "con carácter exclusivo" de este apartado 1 del art. 78 del Estatuto. En una breve pero correcta argumentación, dicho Tribunal, en el FJ $33^{\circ}$, entiende que "tratándose de derechos fundamentales, las garantías establecidas en los arts. 53 y $54 \mathrm{CE}$ han de serlo frente a todos los poderes públicos, pues a todos ellos, sin excepción, vinculan y someten". De este modo, la garantía del Defensor del Pueblo "ha de comprender a cualesquiera Administraciones públicas en aras de la perfecta cobertura de las garantías constituciones de los derechos respecto de todas las variables del poder público". La "Administración" del art. 54 CE, prosigue el Tribunal, no es la concreta especie "Administración central", sino el género en el que se comprende todo poder público distinto de la legislación y la jurisdicción. El corolario de dicha argumentación no puede ser otro que considerar inconstitucional y nulo esa exclusividad que proclamaba el precepto estatutario. Por lo tanto, el Defensor del Pueblo también es competente para supervisar la Adminstración autonómica catalana.

De todos modos, la cuestión todavía está en parte abierta pues falta que se resuelva, entre otros, el recurso de inconstitucionalidad presentado por el Defensor del Pueblo contra dicho Estatuto, y en el que también se consideraba inconstitucional la supervisión de la Administración local de Cataluña por parte del Síndic (art. 78.1 del Estatuto). Asimismo, el Defensor estatal también recurrió ante el Tribunal Constitucional la Ley 24/2009, del Sindic de Grenges de Cataluña, recurso que fue admitido trámite ${ }^{43}$. A la espera de que todo ello traiga mayores concreciones, lo que sin duda ha reforzado la STC 31/2010 ha sido la competencia general del Defensor estatal en todo el territorio. Y ello por un motivo de singular envergadura: la propia garantía de los derechos fundamentales.

43 El Defensor estatal ha recurrido la condición que esta ley atribuye al Síndic de autoridad catalana para la prevención de la tortura y de otros tratos o penas crueles, inhumanos o degradantes, al entender que ello también forma parte de sus competencias en todo el territorio español. 


\section{CONCLUSIONES}

El análisis que hemos desarrollado hasta este momento nos permite concluir que resulta necesario mejorar, impulsar y reforzar las relaciones entre el Defensor del Pueblo y las defensorías autonómicas para logar un adecuado cumplimiento de las funciones propias de la figura del Ombudsman en España. En ello, la preponderancia y el rol dinamizador le deben corresponder al Defensor estatal, como órgano constitucional y, por lo tanto, como figura con una legitimidad cualitativamente distinta.

La cordialidad y la buena predisposición que a nivel personal existe en este ámbito deberían facilitar la mejora jurídica de la situación actual, que puede calificarse de insatisfactoria ${ }^{44}$. La normativa resulta imprecisa y un tanto difusa a la hora de fijar con nitidez los principios jurídicos de relación. Adolece de falta de rigor técnico-jurídico y de bases dogmáticas sólidas. El art. 2 de la Ley 36/1985 es buen ejemplo de ello. Pero entiéndasenos bien: no estamos sugiriendo encorsetar el funcionamiento de unas instituciones que hacen de la flexibilidad una de sus cualidades, ni mucho menos. Tan sólo abogamos por una reconstrucción eficaz y pragmática de dicha flexibilidad, que permita sumar voluntades y compromisos, aclarando las oscuridades actuales y los desajustes presentes. Esa es la opción más racional para el correcto cumplimiento de las funciones de los ombudspersons en un entramado complejo como es el que el Estado autonómico ha deparado en el sector público. De ahí que cobre singular relieve el talante personal de los titulares de estas instituciones y las relaciones que a nivel personal se producen entre aquellos que están al servicio de las mismas.

En este orden de cosas, por ejemplo, sería interesante profundizar en el terreno de la coordinación y cooperación para tratar de aunar criterios de decisión o pautas de conducta, que en diversos ámbitos no coinciden. La previsión constitucional de igualdad sustancial de los ciudadanos en todo el territorio aconseja vivamente esta profundización que busque acercar los criterios de decisión. Asimismo, habría que avanzar en la mejora de la información recíproca para evitar, por ejemplo, que recaigan dos resoluciones sobre el mismo asunto (un peligro, como ya hemos dicho, que actualmente existe en el ámbito de la Administración autonómica y local por la ausencia de canales permanentes y automatizados de información). La implementación de una intranet o de canales reales y permanentes de comunicación ayudaría a ello.

La posible reforma de la LO del Defensor del Pueblo, sugerida por parte de la doctrina ${ }^{45}$, para distribuir campos de actuación entre el Defensor estatal

44 Parte de la doctrina también comparte este análisis crítico. Así, por ejemplo, se ha dicho que el grado de "indefinición en el alcance de las competencias respectivas merma considerablemente la eficacia que la existencia de un doble mecanismo de control orgánico no jurisdiccional hacía presagiar" (BASTIDA FREIJEDO, F., et alii, Teoría General de los derechos fundamentales en la Constitución española de 1978, Tecnos, Madrid, pág. 199).

45 DíEZ BUESO, L., Los defensores del pueblo..., op. cit., págs. 223-224. 
y las defensorías autonómicas, como reflejo del reparto competencial del Estado Autonómico, aportaría, sin duda, claridad, pero a día de hoy chocaría con la doctrina que marca la STC 31/2010 (cuya raíz dogmática ya la comentamos: el Defensor del Pueblo, como órgano del Estado global, no central, se extiende a todas las Administraciones).

En fin, los nuevos retos que el siglo XXI depara a los derechos fundamentales pueden ser enfrentados con eficiencia desde los ombudspersons habida cuenta sus características, que aportan flexibilidad, rapidez de reacción y sumariedad. Fortalecer, con el criterio adecuado, las relaciones entre el Defensor del Pueblo y las defensorías autonómicas semeja una labor imprescindible en esta actualización del papel de este tipo de órganos, sujetos siempre a un permanente y necesario aggiornamento. De este modo, se mostrará su compromiso con una sociedad democrática avanzada y con las esperanzas que la ciudadanía deposita en ellos.

TitL: Federal Ombudsman and autonomous ombudsman offices in Spain: Reflections on their relations and reciprocal position.

ABSTRACT: Relations among the Federal Ombudsman and the Ombudsmen of autonomous territories is a very important issue to acomplish the tasks they were asigned for. The overlapping risk presented by the authorities, and their consequent maladjustments, demand a satisfactory solution to such problematic. The juridical principles that govern such relations aren't embodied neither precisely nor clearly in the applicable law. This issue reinforces the role of personal relations which are already relevant for this bodies to work out. Then, it's recommended to strenghten and to redefine this relations (which are expressed in multiple aspects) according to a sharper and better stablished juridical criteria.

RESUMEN: La relaciones entre el Ombudsman estatal y los ombudsmen autonómicos es un tema de suma relevancia para el adecuado ejercicio de las funciones que tienen asumidas. El riesgo de solapamiento que presentan las competencias concurrentes, y los desajustes que de ello se derivan, exigen una solución satisfactoria a tal problemática. Los principios jurídicos que rigen estas relaciones no están recogidos con precisión y claridad en la normativa aplicable. Ello refuerza el papel de las relaciones personales, de por si muy relevante en el funcionamiento de estos órganos. Así las cosas, se recomienda reforzar y replantear, a partir de criterios jurídicos más nítidos y mejor construidos, estas relaciones, que se manifiestan en múltiples vertientes.

KeY WoRDS: Ombudsman. Autonomous Ombudsman Offices. Coordination. Cooperation. Collaboration. Personal relations.

Palabras Clave: Defensor del Pueblo. Defensorias autonómicas. Coordinación. Cooperación. Colaboración. Relaciones personales.

FECHA DE RECEPCIÓN: 11.05.2010. FECHA DE ACEPTACIÓN: 28.07.2010. 